\title{
Neutral current compensation techniques in autonomous wind energy sources
}

\author{
Aarti Gupta $\cdot$ Dinesh Jain $\cdot$ Surender Dahiya
}

Received: 23 January 2014/ Accepted: 30 June 2014/Published online: 2 August 2014

(c) The Author(s) 2014. This article is published with open access at Springerlink.com

\begin{abstract}
The problem of neutral current compensation has to be addressed in Wind Energy integrated weak microgrids. This study analyses two types of techniques possible for implementation of neutral current compensation by drawing a comparative research of their application on the same wind energy conversion system. The hybrid microgrid considered in the study comprises a synchronous diesel generator and an inverter-based wind generator. The results and analysis are conducted by time-domain simulations using MATLAB/Simulink software. The use of electronic power converters that also act as an active neutral current compensator or a zig-zag transformer connected with the load mitigates the problem of neutral current compensation to a large extent. The voltage unbalance factor is also significantly reduced due to neutral current compensation and power quality is enhanced. The results provide the actual operational limits possible under the set of given constraints.
\end{abstract}

Keywords Micro-grid · Wind energy conversion system (WECS) $\cdot$ Zig-zag transformer

\section{Introduction}

The third world countries face severe power crunch due to shortage of generation and some areas are totally devoid of

\footnotetext{
A. Gupta $(\square)$

Department of Electrical, HCE, Industrial Area, Sonipat, India e-mail: aartigupta45@gmail.com

D. Jain $\cdot$ S. Dahiya

Department of Electrical, Deen Bandu University of Science and Technology, Murthal, India
}

grid connectivity. Autonomous generation with renewable micro-sources provide a cost-effective and environment friendly solution. Most of the research based on the autonomous operation of wind energy conversion system (WECS) basically verified the efficacy of the system for three-phase balanced loads [1-4]. In practical applications, the three-phase four-wire systems are associated with problems as regards to the poor voltage regulation, high reactive power consumption and harmonics current burden, load unbalancing and significant neutral currents, etc. The non-linear input characteristic of typical loads like computers and electronic equipment, connected to the threephase four-wire distribution power systems creates a problem of high input current harmonics. Since wind is an intermittent source of energy, it is integrated with a diesel generator which serves as an alternate source of energy. Micro-grids are systems with clusters of loads and microsources [5-8]. If the micro-grid is wind based, the high penetration of wind energy along with different types of loads is a cause for power quality issues. The problem of unbalanced voltages is more pronounced in autonomous generation as the micro-grid is weak and more susceptible to changes in the load current. Since actual load demands necessitate a scheme to reduce the effect of unbalancing, various control schemes are used to compensate the neutral. In Tamil Nadu state of India, the current unbalance is very low in Radhapuram, despite the relatively high voltage unbalance as the phase currents are controlled actively in the IGBT-based power converters in the wind turbines.

The key issues responsible for the effectiveness of the penetration of renewable are mainly pertaining to their capacity to compensate for current pollution due non-linear as well as reactive load. Strict power quality standards have led to a lot of research in this field. Various methodologies can be affected for compensation. The zig-zag transformer 
can also be used to provide a cost-effective and simple solution to mitigate neutral currents and in autonomous wind-based generation systems, its role in providing neutral current compensation has also been investigated [9, 10]. For certain applications, there is a possibility of providing compensation by changing the operating parameters. Active power filters (APFs) are widely used for this purpose but the additional converters required for the purpose increase the overall cost of the system [11-17].

The WECS adopt an AC-DC-AC converter system with voltage-source converters (VSCs) or current-source converters (CSCs). The inverter itself can be used as an active filter, and using the fourth leg of the inverter, the neutral current can also be compensated while providing additional benefit of improving the power quality [18]. In the present scenario, the WECS are supposed to provide power for both active as well as reactive loads. Therefore, the WECS can now be actively controlled to enhance the system stability with improved power quality at the point of common coupling (PCC) with weak micro-sources (diesel generator or small hydro-based generation) [19].

Though compensation schemes are available, no comparative research of their application on the same WECS has been conducted. The paper compares the two commonly used control schemes of neutral current compensation by means of inverter and using the transformer. MATLAB/ Simulink was used to compare the two compensation methodologies. Behavior of the WECS was analyzed for unbalanced and non-linear loads, which may result in an overloading of the neutral conductor. The simulation results validated that the total active power supplied is considerably reduced while achieving active current compensation through inverter. Hence, this mode of operation is beneficial only when high power quality standard is required. Zig-zag compensation increases the wind penetration resulting in reduced dependence on an alternative power source. The contents are arranged as follows. A brief modeling of the control topology for active current compensation is detailed at first. Details of zig-zag compensation are included in the next section. There is a brief description of the converter control followed by MATLAB results and conclusion.

\section{Neutral current compensation}

Neutral current compensation can be achieved through the inverter by either connecting a zig-zag transformer or by current control of the inverter.

Active current compensation

The system under consideration is shown in Fig. 1, where a permanent magnet synchronous generator (PMSG) based wind turbine generator (WTG) is connected on the Dc link of grid interfacing 4-leg inverter. The fourth leg of inverter is used to compensate the neutral current of three-phase four-wire network. Control description is shown in Fig. 2. The inverter serves the dual purpose of delivering the power from renewable source to load and also solves the power quality problem arising due to unbalanced non-linear load at PCC. The renewable source used for the study is wind energy. The secondary energy source is served by a diesel engine driving a synchronous generator.

The error between reference Dc-link voltage $\left(V_{\mathrm{dc}} *\right)$ and actual Dc-link voltage $\left(V_{\mathrm{dc}}\right)$ is given to the proportionalintegral (PI) controller with gains $k_{\mathrm{p}}$ and $k_{\mathrm{i}}$, respectively. The reference $\mathrm{d}$-axis current $\left(i_{\mathrm{d}} *\right)$ is thus generated, while the Reference q-axis current $\left(i_{\mathrm{q}}{ }^{*}\right)$ is set to zero for unity power factor (UPF) operation.

$i_{\mathrm{d}}^{*}=k_{\mathrm{p}}\left(V_{\mathrm{dc}}^{*}-V_{\mathrm{dc}}\right)+k_{\mathrm{i}} \int\left(V_{\mathrm{dc}}^{*}-V_{\mathrm{dc}}\right)$

The grid synchronizing angle $\left(\theta_{\mathrm{e}}\right)$ obtained from phase lock loop (PLL) is used to generate the reference microgrid currents $\left(i_{\mathrm{sa}}{ }^{*}, i_{\mathrm{sb}} *\right.$, and $\left.i_{\mathrm{sc}} *\right)$. The reference neutral current $\left(i_{\mathrm{sn}}{ }^{*}\right)$ is set to zero to achieve balanced current operation. The PWM current controller is used to enable the micro-grid currents $\left(i_{\mathrm{sa}}, i_{\mathrm{sb}}\right.$, and $\left.i_{\mathrm{sc}}\right)$ to track the reference currents enabling it to supply only the fundamental active power, while the wind interfacing inverter fulfills the unbalanced reactive and non-linear current requirements of three-phase four-wire load at PCC.

\section{Hybrid micro-grid with zig-zag compensation}

The neutral currents have many harmful effects which are well documented such as overheating of the power systems components. Unbalanced loading conditions are created by accessing the neutral leg of the transformer and then loading the three phases with unequal loads as shown in Fig. 3. In the three-phase four-wire distribution power system, the three-phase zero-sequence currents $\left(I_{\mathrm{ao}}, I_{\mathrm{bo}}\right.$, and $\left.I_{\mathrm{co}}\right)$ have the same amplitude and the same phase.

$I_{\mathrm{ao}}=I_{\mathrm{bo}}=I_{\mathrm{co}}$

And the neutral current $I_{\mathrm{n}}$ is represented by

$I_{\mathrm{n}}=3 I_{\text {ao }}$

The necessary neutral current which is required by the load is supplied by the zig-zag transformer. The true definition of the voltage unbalance factor (VUF) involves both magnitude and angles (complex algebra). When calculating the positive and negative sequence voltage components a simpler formula given by the following equation.

$\mathrm{VUF}=82 \sqrt{\left(v_{\mathrm{abe}}\right)^{2}+\left(v_{\mathrm{bce}}\right)^{2}+\left(v_{\text {cae }}\right)^{2}} / v_{\mathrm{avg}}$ 


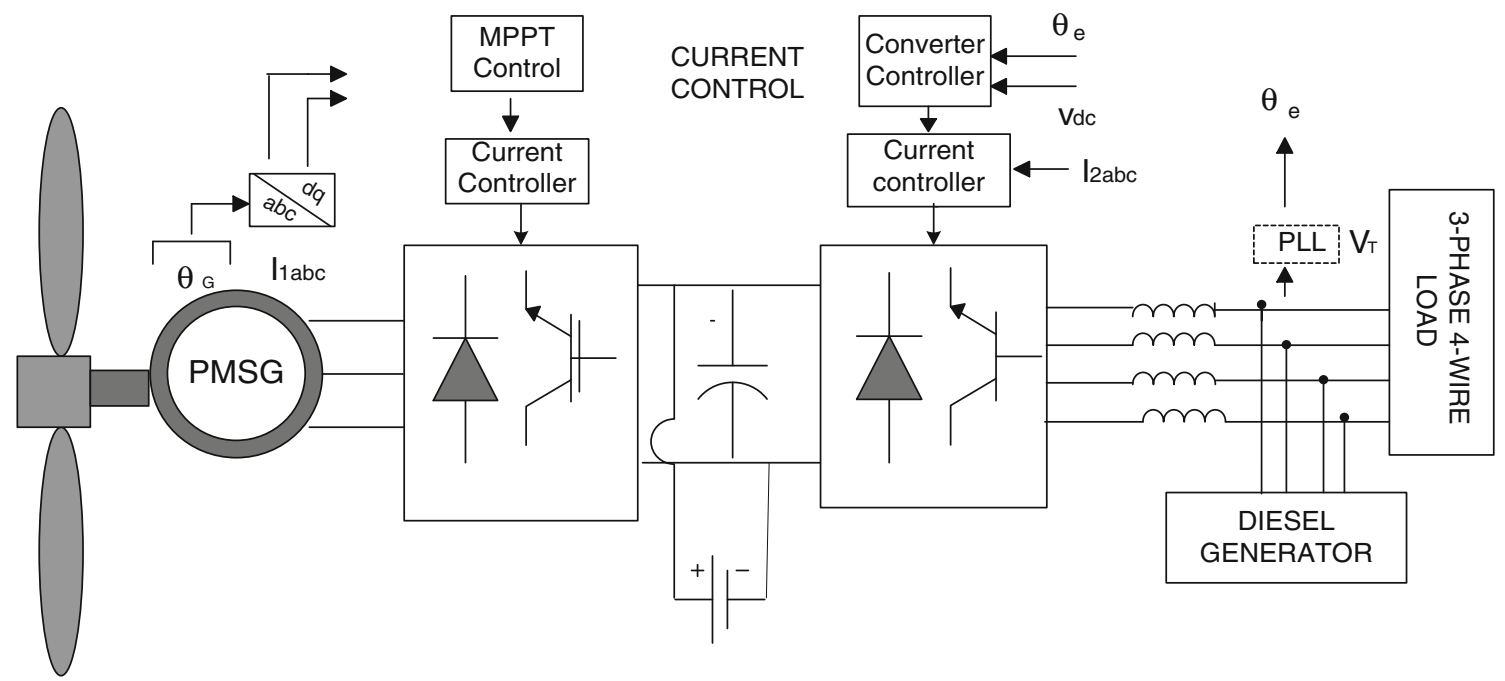

Fig. 1 Schematic of active inverter control

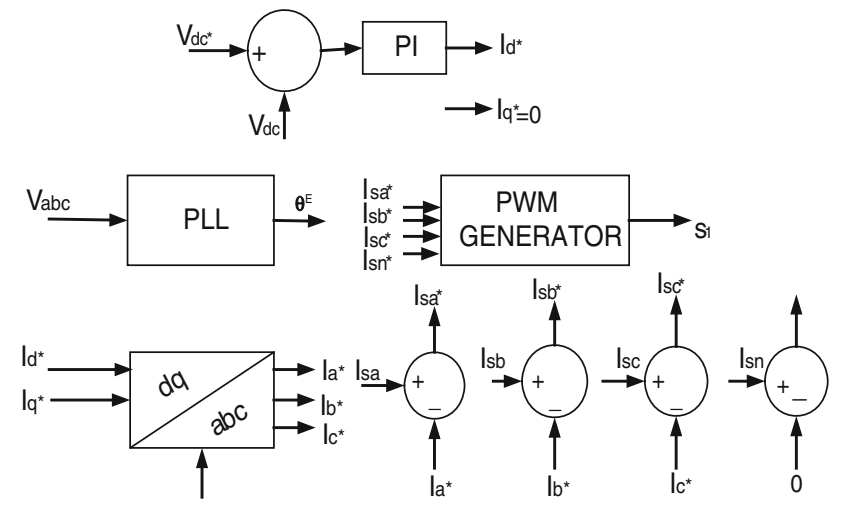

Fig. 2 Inverter controller for current compensation

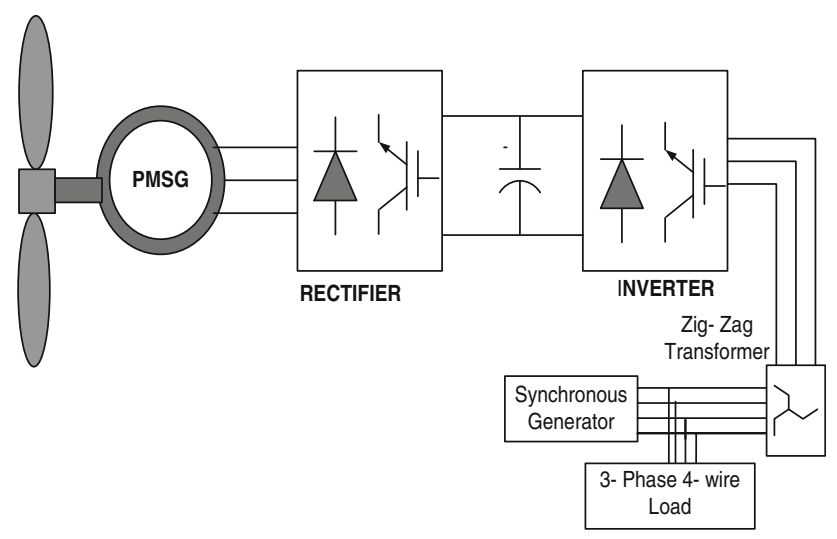

Fig. 3 Schematic with zig-zag compensation

where, $v_{\text {abe }}$ is the difference between the line voltage $V_{\mathrm{ab}}$ and the average $v_{\text {avg }}$ line voltage, $v_{\text {bce }}$ is the difference between the line voltage $V_{\mathrm{bc}}$ and the average $v_{\mathrm{avg}}$ line

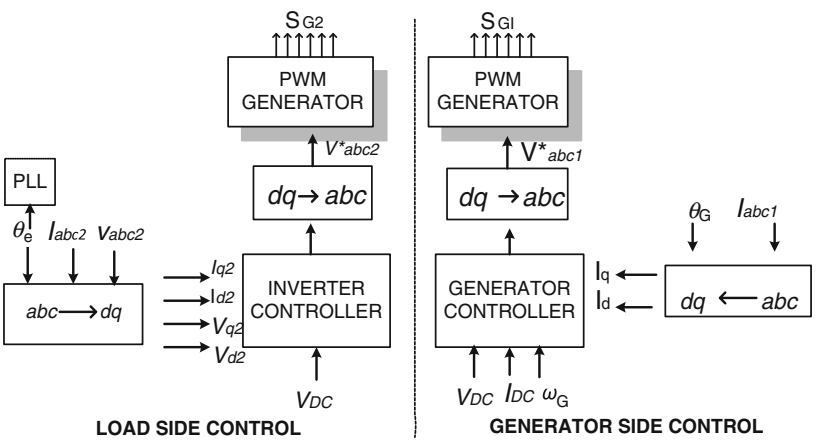

Fig. 4 Converter control

voltage, $v_{\text {cae }}$ is the difference between the line voltage $V_{\text {ca }}$ and the average $v_{\text {avg }}$ line voltage.

It avoids the use of complex algebra but gives a good approximation to the true definition $\%$ voltage unbalance [20].

The active power supplied by the WECS is not compromised in case of current compensation by zig-zag control. Except for the Triplen harmonics, other harmonics remain in the current waveform.

\section{Modeling of converters}

A salient-pole synchronous machine is used to achieve efficient operation of the PMSG. The control diagram for the same is described in Fig. 4 with the help of the following equations. The voltage equations governing the model are derived as follows. In a variable speed, WECS the maximum power at different wind velocities is almost a cubic function of generator speed. For maximum power point tracking (MPPT), the reference speed $\omega^{*}$ is obtained using a cubic root function. 
$\omega^{*}=\sqrt[3]{P_{\mathrm{DC}}}$

$P_{D C}$ is the measured power across the DC link and is a product of $V_{\mathrm{DC}}$ (DC-link voltage) and $I_{\mathrm{DC}}$ (DC-link current). Reference torque $T e^{*}$ of the generator is obtained as the output of the proportional-integral (PI) controller with gains $K_{\mathrm{p} 1}$ and $K_{\mathrm{i} 1}$, respectively. The error of this reference speed and actual speed $(\omega)$ is the input to the (PI) regulator.

$T e^{*}=\left(K_{\mathrm{p} 1}-K_{i 1} / s\right)\left(\omega^{*}-\omega\right)$

Thus, the reference quadrature axis current $i_{\mathrm{q}} *$ can be obtained by Eq. 7.

$I_{\mathrm{q}}^{*}=4 / 3\left(T e^{*} / P \Psi\right)$

where ' $P$ ' is the number of pole pairs of the PMSG and ' $\psi$ ' is the flux, respectively. The direct-axis current $I_{\mathrm{d}} *$ is set to zero for UPF operation. The reference $V_{\mathrm{d}}{ }^{*}$ and $V_{\mathrm{q}}{ }^{*}$ the outputs of other PI controllers are compared to $V_{\mathrm{d} 1}$ and $V_{\mathrm{q} 1}$ obtained from abc to dq transformation of $V_{\text {abc1 }}$ (generated voltage). Thus, the reference $V_{\mathrm{abc1}} *$ is input to the PWM generator which generates the control signal SG1 of the rectifier.

The load-side converter control is realized using synchronous reference frame (SRF) technique, the DC-link voltage $\left(V_{\mathrm{DC}}\right)$ is controlled by the grid-side inverter. The active power exchange is directly proportional to the direct-axis current $i_{\mathrm{d} 2}$ which is also responsible for regulating the DC-link voltage. Figure 4 shows the control topology. The grid-side converter control is realized using an SRF, the DC-link voltage, $V_{\mathrm{DC}}$ is controlled by the grid-side inverter. The $V_{\mathrm{DC}} *$ is set to $1,000 \mathrm{~V}$. The voltage equation can be derived as follows. If $V_{\mathrm{abc} 2}$ are the DG voltages and $L$ is the coupling inductance. In the d-q frame of reference, $V_{\mathrm{abc2}}$ are converted to $V_{\mathrm{d} 2}$ and $V_{\mathrm{q} 2}$ with the help of PLL.

To operate at UPF, the value of $i_{\mathrm{q} 2} *$ is set to zero. The active power exchange is directly proportional to the $i_{\mathrm{d} 2}$ and this direct-axis current, $i_{\mathrm{d} 2}$ is also responsible for regulating the Dc-link voltage. For decoupled control, the system equations are given as follows

$V_{\mathrm{d} 2} *=V_{\mathrm{d} 2}+\omega L i_{\mathrm{q} 2}-\Delta v_{\mathrm{q}}$

$V_{\mathrm{q} 2} *=V_{\mathrm{q} 2}-\omega L i_{\mathrm{d} 2}-\Delta v_{d}$

where $\Delta v_{\mathrm{q}}$ and $\Delta v_{\mathrm{d}}$ are calculated as follows

$$
\begin{aligned}
& \Delta V_{\mathrm{d}}=K_{\mathrm{P}}\left(i_{\mathrm{d} 2}^{*}-i_{\mathrm{d} 2}\right)+K_{\mathrm{I}} \int\left(I_{\mathrm{d} 2}^{*}-i_{\mathrm{d} 2}\right) \\
& \Delta v_{\mathrm{q}}=K_{\mathrm{P}}\left(I_{\mathrm{q} 2}^{*}-i_{\mathrm{q} 2}\right)+K_{\mathrm{I}} \int\left(I_{\mathrm{q} 2}^{*}-i_{\mathrm{q} 2}\right)
\end{aligned}
$$

The reference voltages $V_{\mathrm{d} 2} *$ and $V_{\mathrm{q} 2} *$ obtained from Eqs. 8 and 9 are transformed into reference voltages
$\left(V^{*}\right.$ abc2). The output is given to the PWM generator which generates controlled pulses $\mathrm{S}_{\mathrm{G} 2}$ for the IGBT inverter.

\section{Discussion and analysis of results}

Analysis of the results of MATLAB simulations of the inverter control topology shows that if an unbalanced nonlinear load is applied on the three-phase four-wire system, a significant current flows in the supply neutral. The system response is tested for both the neutral compensation control schemes on a $20 \mathrm{KW}$, PMSG.

Results of neutral current compensation by inverter control

In Fig. 5, the DC-link inverter is used to provide the neutral current compensation as well as the active power. The inverter supplies the requisite neutral current $\left(I_{\text {Inv }}\right)$ and the neutral current supplied by the diesel generator $\left(I_{\text {grid }}\right)$ is almost negligible. For a period of 1-1.2 s, the non-linear unbalanced load currents $\left(I_{\text {load }}\right)$ are also shown. Since the major part of the non-linear current is due to harmonic components, the harmonic current compensation from the inverter $\left(I_{\text {inv }}\right)$ also helps to improve the current from the integrated supply $\left(I_{\text {grid }}\right)$. It clearly shows that the inverter reduces the current pollution at the PCC due to non-linear load. The neutral current of the micro-source is shown in black color along with the three-phase currents $\left(I_{\text {grid }}\right)$. The inverter current $\left(I_{\text {inv }}\right)$ provides the necessary neutral current along with harmonic compensation which improves the current profile of the grid.

The inverter performs dual function of supplying the load current and the necessary neutral current. For a period of $1-5 \mathrm{~s}$, the non-linear unbalanced load current $\left(I_{\mathrm{L}}\right)$ is also shown. The voltage at the DC link is maintained constant at $400 \mathrm{~V}$, the neutral current drawn by the load $\left(I_{\text {ln }}\right)$ is supplied by the inverter. Hence $I_{\mathrm{INVN}}$, the inverter neutral current is nearly $10 \mathrm{~A}$ as shown by the figure whereas the neutral current drawn from the interconnected supply $\left(I_{\mathrm{SN}}\right)$ is negligible. Based on the results, it can be established that inverter can be used to supply the necessary neutral current without burdening the alternative source of supply, i.e., the diesel unit. Hence, wind power satisfies the power quality requirements as well as the active power demand of the load.

Results of neutral current compensation by zig-zag transformer

An unbalanced linear load as well as non-linear load is applied at the PCC to test for neutral current compensation. 


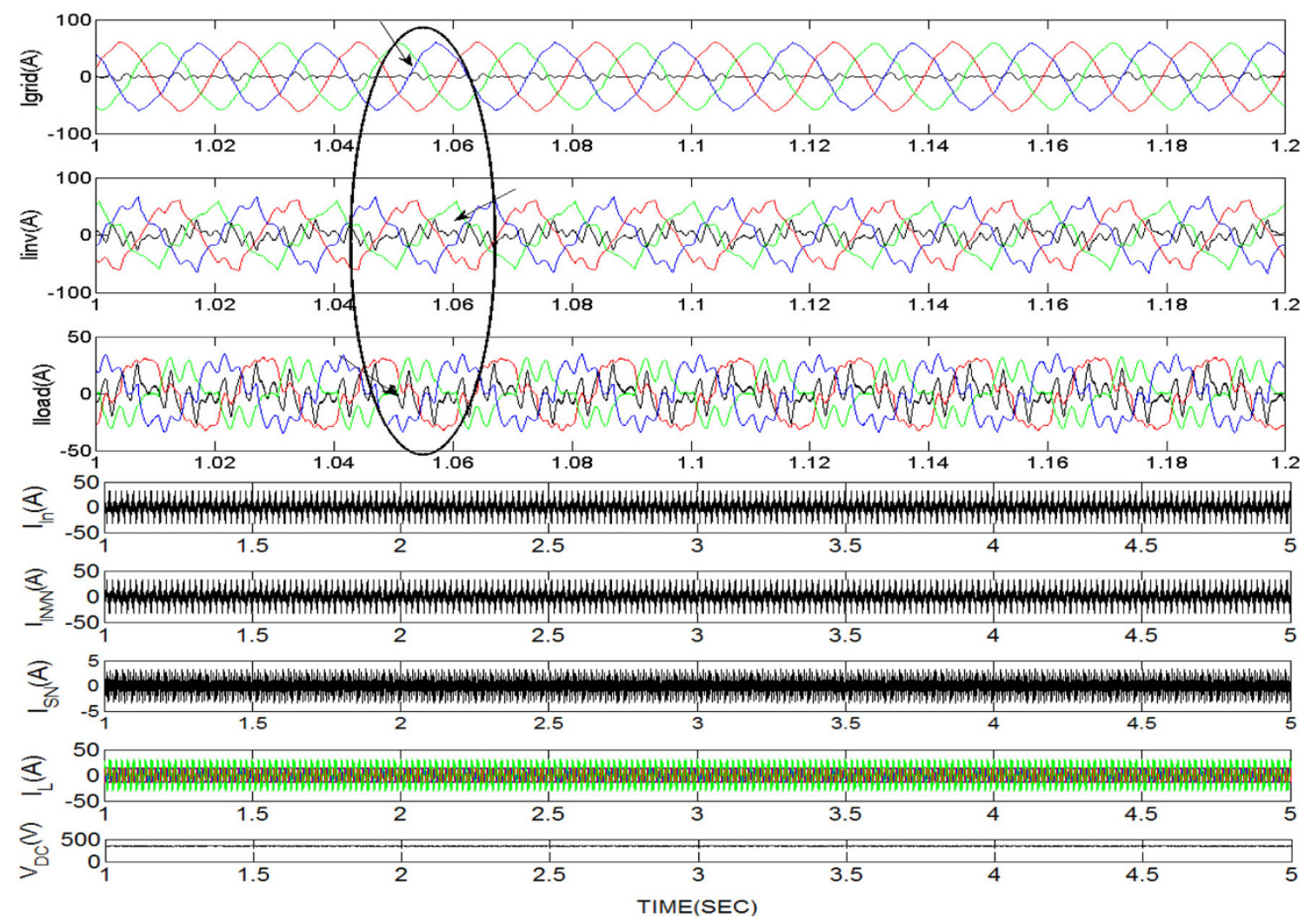

Fig. 5 Results for inverter current compensation

After the zig-zag transformer is switched by means of a breaker at $t=2 \mathrm{~s}$, the current in the supply neutral $\left(i_{\mathrm{sn}}\right)$ is significantly reduced and validated by Fig. 6 . The load neutral current is nearly $10 \mathrm{~A}$ which is entirely compensated by $I_{\mathrm{ZN}}$, the zig-zag neutral current which is $10 \mathrm{~A}$ at $t=2 \mathrm{~s}$.

In case of linear unbalanced loads $\left(I_{\mathrm{L}}\right)$, magnitude of set of voltages $\left(V_{\mathrm{PCC}}\right)$ is also unbalanced. The switching of the zig-zag transformer improves the VUF. As shown by the result, the voltage profile is also improved at $t=2 \mathrm{~s}$. The switching of the transformer reduces the voltage unbalance to $1.15 \%$ from $3.5 \%$ which is well within the specified limits of $3 \%$, as per power quality standards.

The current is redistributed, reducing the current magnitude unbalance of the autonomous WECS in case of unbalanced loads. The VUF is calculated using the formula given by Eq. 4 in the previously described control scheme. Voltage control of converters results in greater efficiency and loss reduction.

The results of zig-zag compensation for unbalanced non-linear load indicate that though the current pollution at the PCC is not improved significantly, the neutral current of the load is adequately compensated. When the zig-zag transformer is switched on the elimination of triplen harmonic reduces pollution at the grid as indicated by the grid currents $\left(I_{\mathrm{G}}\right)$. This scheme is preferred if greater wind penetration is desirable and economy is an issue. If stringent adherence to standards is required and current quality of the micro-grid needs to be improved, then compensation through inverter is a better choice as barring third harmonic all other harmonics remain in the current waveform.

\section{Conclusion}

In applications where active power supply is of prime importance, simple and economical inclusion of zig-zag transformer improves the performance of the autonomous WECS and attenuates the neutral current in case of unbalanced loads. The economic viability of zig-zag transformer makes it an attractive proposition in case of small autonomous units because in addition to providing neutral compensation it additionally attenuates the third harmonic pollution of the supply current. The neutral current compensation provided by the inverter provides harmonic compensation and significantly reduces the current pollution at the PCC. It is useful when high power quality standards are desirable in autonomous operation. 

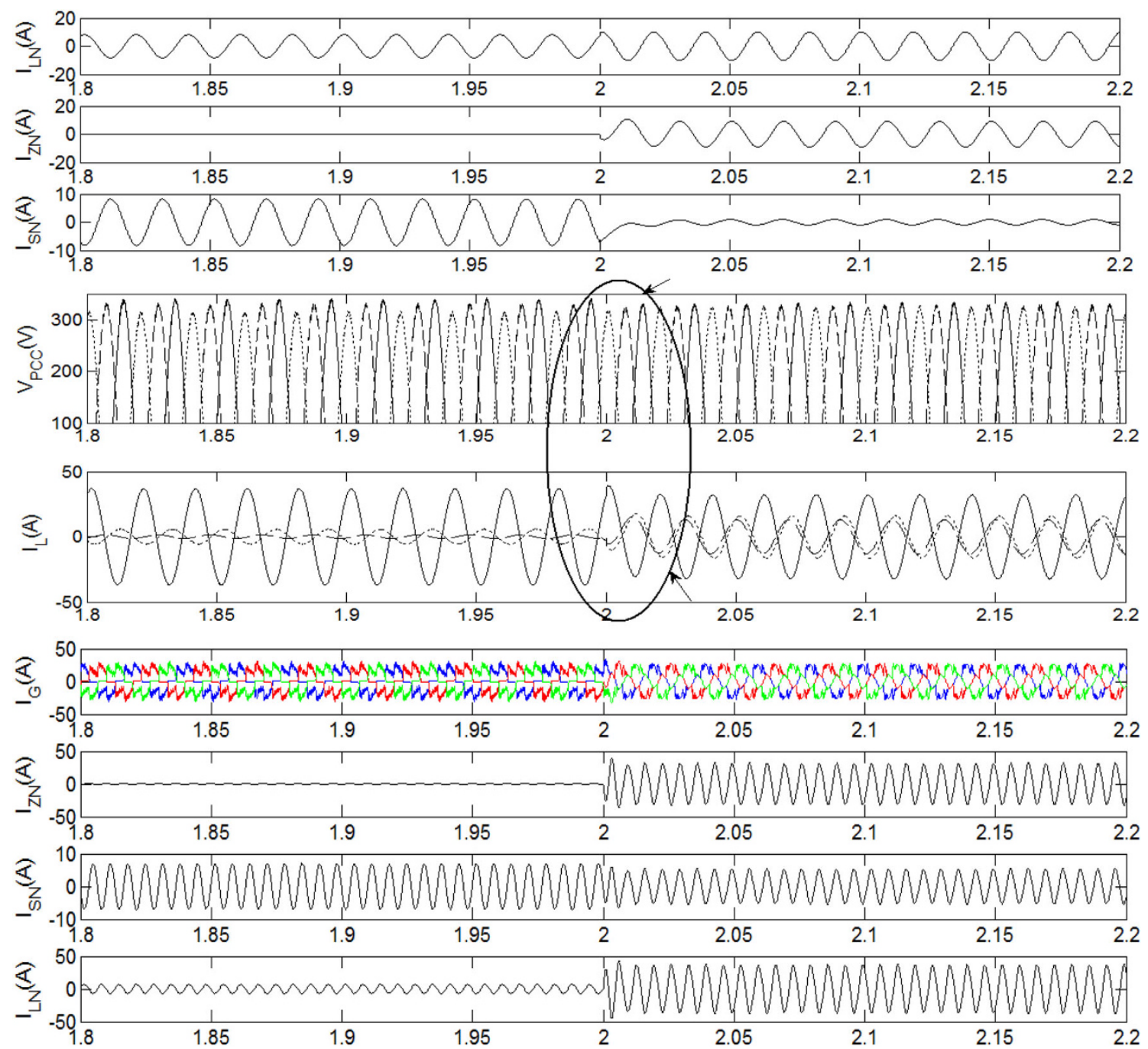

Fig. 6 Results of current compensation by zig-zag transformer

The simulation results indicate that either of the two schemes can be used based on the applicability.

Acknowledgments The author thanks DCRUST, Murthal for providing software support for this research.

Conflict of interest The authors declare that they have no competing interests.

Authors' contributions A. Gupta and D.K. Jain contributed equally to this work.

Open Access This article is distributed under the terms of the Creative Commons Attribution License which permits any use, distribution, and reproduction in any medium, provided the original author(s) and the source are credited.

\section{References}

1. Cristea, C., Lopes, J.P., Eremia, M., Toma, L.: The control of isolated power systems with wind generation. In: Proceedings of IEEE Power Technology conference, pp. 567-572 (2007)
2. Singh, M., Chandra, A.: Control of PMSG based variable speed wind- battery hybrid system in an isolated network. IEEE Trans. Energy Convers. 16, 134-139 (2009)

3. Mohammad, A., Haruni, O., Gargoom, A., Enamul Haque, Md.: Diesel hybrid remote area power systems. In: Proceedings of Australian Power Energy conference, AUPEC, pp. 1-7 (2009)

4. Majid, V., Omid, R., Marc, A. R., Farivar, F., Pooyandeh.: Application of sliding window technique for prediction of wind velocity time series. Int. J. Energy. Environ. Eng. 5, 1-7 (2014)

5. Haque, E., Muttaqi, K., Negnevtsky, M.: A control a stand alone variable speed wind turbine with a permanent magnet synchronous generator. In: Proceedings of PES, IEEE Power and Energy Society, Montreal, pp. 1-9 (2008)

6. Lal, S., Raptor.: A Techno-economic analysis of a hybrid minigrids system for Fiji islands. Int. J. Energy Environ. Eng. 3 (2012)

7. Islam.: Increasing wind energy penetration level using pumped hydro storage in island micro-grid system. Int. J. Energy Environ. Eng. 9, 1-10 (2012)

8. Partha, K., Chandan, K.: A simple and fast approach for allocation and size evaluation of distributed generation. Int. J. Energy Environ. Eng. 4, 1-7 (2013)

9. Jou, H.L., Wu, J.C., Wu, K., Chiang, W.J., Chen, Y.H.: Analysis of zig-zag transformer applying in the three-phase four-wire 
distribution power system. IEEE Trans. Power Deliv. 20, 1168-1173 (2005)

10. Shahnia, F., Ghosh, A., Ledwich, G.: Operation and control of a hybrid microgrid containing unbalanced and nonlinear loads. Elsevier Electr. Power Syst. Res. 80, 828-837 (2011)

11. Inoue, S., Shimizu, T., Wada, K.: Control methods and compensation characteristics of a series active filter for a neutral conductor. IEEE Trans. Ind. Electron. 54, 433-440 (2007)

12. Mishra, M.K., Karthikeyan, K.: An investigation on design and switching dynamics of a voltage source inverter to compensate unbalanced and nonlinear loads. IEEE Trans. Ind. Electron. 56, 2902-2908 (2009)

13. Vodyakho, O., Mi, C.C.: Three-level inverter-based shunt active power filtering three-phase three-wire and four-wire systems. IEEE Trans. Power Electron. 24, 1350-1363 (2009)

14. Xia, C., Gu, Xin, Shi, T., Yan, Y.: Neutral-point potential balancing of three-level inverters in direct-driven wind energy conversion system. IEEE Trans. Energy Convers. 26, 18-29 (2011)
15. Bhattacharya, S., Frank, T.M., Divan, D.M., Banerjee, B.: Active filter system implementation. IEEE Ind. Appl. Mag. 4, 47-63 (1998)

16. Singh, B., Al-Haddad, K., Chandra, A.: A review of active filters for power quality improvement. IEEE Trans. Ind. Electron. 4, 133-138 (2008)

17. Singh, M., Khadkikar, V., Chandra, A., Varma, R.K.: Grid interconnection of renewable energy sources at the distribution level with power-quality improvement. IEEE Trans. Power Deliv. 26, 307-315 (2011)

18. Kasal, G., Singh, B.: Zig-Zag transformer for neutral current compensation in an isolated wind energy system. Int J. Power Energy Convers. 3, 220-227 (2012)

19. Puneet, K. G., Bhim, S., Murthy, S.S., Navin, K.: Autonomous three phase four wire hybrid system using PMSGs for hydro and wind power generation. In: Proceedings of IEEE Ind. Elect. IECON 35th Annual Conference, pp. 255-260 (2009)

20. Pillay, P., Manyage, M.: Definitions of voltage unbalance. IEEE Power Eng. Rev. (2001) 